tung“", 4 Bde., 1876-86); sein Projekt für eine Gehöftanlage wurde in der Land- und forstwirtschaftl. Ausst. in Wien 1890 mit der silbernen Medaille prämiert. Später erbaute er auch Mietshäuser, einige gem. mit dem Baumeister Johann Zoufal in Brünn. Als Architekt verwendete er eine breite Stilpalette des Späthistorismus. Im Neugot. Stil baute er die Kirche St. Florian (gem. mit Vojtěch Dvořák und Karel Welzl, 189899) und das Pfarrhaus von St. Jakob (1900 02). Im Stil der italien. Neorenaissance projektierte er in Brünn das Dt. Haus (2. Preis, 1886, nicht realisiert) und das Allg. K. Franz Joseph-Versorgungshaus (1888-89). Eine neobarocke Formensprache wählte er für die Villa Langer (1888-91), im Stil der dt. Neorenaissance wurde die Bibl. (1892) sowie im klassizist. Barock die Sparkasse erbaut (alle Zwittau). Eklektizismus zeigt sich an den Fassaden des Mietshauses der Familie Emmer in Mähr. Schönberg (1897) oder im Valentin Gerstbauer'schen Stiftungshaus in Brünn (1899-02). Daneben verf. er Fachbücher, u. a. das mehrfach aufgelegte mehrbändige „Handbuch der Bau-Constructionslehre“" (1873, 2. erw. Aufl. 1877). W. war Mitgl. des Mähr. Kunstver. sowie des Ver. der Baumeister in Mähren und Schlesien und wurde 1898 zum Baurat ernannt. Weiters gehörte er der Jury vieler architekton. Wettbewerbe an, so z. B. für den Brünner städt. Gen.regulierungsplan (1902), und war Mitgl. der Prüfungskomm. für Bewerber um Bau-, Maurer-, Steinmetz-, Zimmer- und Brunnenmeister-Berechtigungen (1894).

Weitere W.: Süderschanzen-Denkmal, 1870 (Eckernförde); Villa mit Wirtschaftsgebäude, 1882 (Tłumacz); Wirtschaftshof, 1882 (Kis-Borsa); Wanniecks Warenhaus, 1883 (Brünn); Evang. Kirche, 1890 (Chrostau).

L.: Tagesbote aus Mähren und Schlesien, 11. 3. 1890, 31. 10., 1., 3. 11. 1904; Jahres-Ber. der k. k. Staats-Gewerbeschule in Brünn 3ff., 1876/77ff.; Dt. Südmährerbl. 2, 1904, Nr. 44, S. 9; Der Bautechniker 24, 1904, S. 1011, 25, 1905, S. 4; P. Zatloukal, in: Vlastivědný věstník moravský 47, 1995, S. 14ff.; M. Magniová, G.W., architekt posledni čtvrtiny 19. století, DA Brno, 1997; P. Genz, Bauen über die Region hinaus. Architekten aus der Baugewerkschule Eckernförde 1868-1968, 2006, S. 12ff.; P. Zatloukal, A Guide to the Architecture of Brno 18151915, 2006, s. Reg.

(J. Galeta)

\section{Wándza (Vándza) von Somkút und} Perecsen Mihály, Schauspieler, Theaterdirektor, Schriftsteller, Maler und Kupferstecher. Geb. Perecsen, Ungarn (Pericei, RO), 12. 10. 1781; gest. Miskolcz (Miskolc, H), 1854; evang. HB. - W. lernte zunächst bei dem Maler Gottfried Neuhauser in Klau- senburg. Anschließend besuchte er 1808 09 gem. mit Pál Balkay, Sámuel Kiss, Elek Marczinkey und Sámuel Nagy die Wr. ABK. In Wien schloss er mit $\rightarrow$ Ferenc v. Kazinczy sowie Emanuel Schikaneder Bekanntschaft. Letzterer scheint maßgebl. Einfluss auf W. ausgeübt zu haben, denn nach der Rückkehr nach Siebenbürgen eröffnete W. 1810 mit Unterstützung von Ilona Baronin Wesselényi v. Hadad ein Theater in Klausenburg. 1812-20 Wanderschauspieler und Dir. der Truppen in Neumarkt, Miskolcz, Szegedin, Debreczin und Großwardein, wirkte W. als Schauspieler, Regisseur und Bühnenmaler. Er spielte u. a. die Titelrollen in William Shakespeares „Hamlet“ und „Macbeth" sowie in Karl Friedrich Henslers „Rinaldo Rinaldini“ und trat auch als Karl in Friedrich Schillers „Die Räuber“ in Erscheinung. Als Regisseur und Bühnenmaler legte er bes. Wert auf Bühnenbilder, szen. Bühnenattraktionen, Ballett- und Tanzeinlagen sowie Lichteffekte. Seine Inszenierungen wurden in der Korrespondenz zwischen $\rightarrow$ Gabriel Döbrentei und Kazinczy ausgesprochen gelobt (1811). Des Weiteren wirkte W. als Dramatiker, u. a. als Autor eines Lustspiels über den ung. Räuberhptm. Márton Zöld (,Zöld Martzi, vagy az úton álló haramia“, 1815). Ab 1820 gestaltete er zwar Bühnenbilder und szen. Attraktionen für die Schauspieltruppen in Miskolcz und Kaschau, war aber theatral. nicht mehr aktiv und befasste sich fast ausschließ1. mit Malerei und Kupferstecherei. So entwarf er u. a. das Titelbl. der berühmten, gegen die Spracherneuerung gerichteten Spottschrift "Mondolat" (1813). Seine Porträts, Stillleben und Historiengemälde $-\mathrm{z}$. B. die 1828 in Pest ausgest. Bildnisse über die erste Begegnung Matthias Corvinus' mit dessen späterer Gemahlin Beatrix v. Aragón bzw. über die Vermählung der ung. Kgn. Maria I. mit Sigismund v. Luxemburg - sind größtenteils verschollen. Das vor einigen Jahren in den Smlgg. des Miskolczer Herman-Ottó-Mus. aufgetauchte Gemälde des ung. Fürsten Kund („Kund vezér") sowie das 1831 entstandene, K. $\rightarrow$ Ferdinand I. darstellende Kniestück (,V. Ferdinánd“, József Attila Múz., Makó) zeugen von einem talentierten Maler.

L. (s. auch Vándza): M. Életr. Lex.; Müvészeti Lex. I, II; Szinnyei; Thieme-Becker; ÚMÉL; Szinészeti lex. 2, 1930; D. Tóth, A magyar népszínmü zenei kialakulása, 1930, passim; Magyar szinmüvészeti lex. 4, 1931; M. Csery-Clauser, in: Erdélyi Múz. 13 (47), 1942, S. 262ff.; D. Pataky, A magyar rézmetszés története, 1951; Szinházi kislex., 1969; Gy. Seregélyi, Magyar festők és gra- 